\title{
Fer i pintar un plat de ceràmica amb un relat amagat que parla sobre la màgia de la trobada dels pares
}

\author{
Xavier Garriga Mora \\ Escola Municipal d'Art Illa de Sabadell \\ xavigarrigamora@gmail.com
}

Resum: Als tallers infantils d'art de l'Escola Municipal d'Art Illa de Sabadell procurem fer treballs significatius que tenen a veure amb les biografies dels nens i les seves famílies. En aquest, hem fet uns plats de ceràmica pintats amb el relat del dia que els pares es van veure per primer cop.

Des de l'antiguitat, la ceràmica sempre ha estat un suport per facilitar la vida $i$ alhora ha estat portadora d'elements simbòlics que acompanyen lesperit de la seva funcionalitat, amb decoracions que donen força i màgia per al viure dels usuaris.

Fer un plat amb fang, commemoratiu, és un acte simbòlic: un plat en què ens menjarem possiblement el nostre futur. Com expliquen Jodorowsky (Jodorowsky $i$ Costa, 2011) i sobretot Stephan Hausner (2013) quan parlen del contracte inicial que fa una parella quan es troba, moltes clàusules complexes dels pares les paguen els fills, que intenten compensar $i$ solucionar coses $i$ ho acaben pagant amb la seva salut.

Aquests tipus de propostes artisticoeducatives desperten relats dintre de les famílies del nostre alumnat, i també professorat, i es produeix a l'escola un fet que sempre ens encomana incloure-hi Carles Parellada des de la pedagogia sistèmica: la reconciliació biogràfica, la creació d’un relat del vincle que ens ajuda a donar sentit i força per viure el present.

Aquesta proposta es va fer amb l'alumnat del màster en Pedagogia Sistèmica a l'Institut Gestalt i la Fundació URV, $i$ ens va permetre descobrir en la pròpia pell la importància d'aquest relat fundacional de la parella que ens va fer. Sigui el que sigui el que va passar entre els pares, si es tracta del nostre origen és prou important saber el que va passar per fer el nostre propi relat present del viure. Es van incorporar moviments sistèmics a través dels quals es van fer emocionants descobriments.

Paraules clau: pedagogia sistèmica; relats del viure; ceràmica; reconciliació familiar; resiliència; tallers infantils d'art.
Abstract: In our children art workshops, in the Municipal Art School Illa de Sabadell, we try to do significant works about children and their parents biographies. In this workshop we have made ceramic dishes and we have painted on them the story of our parents meeting each other for the first time.

Since ancient times, ceramics have always been a support to make life easier and at the same time it has been carrying symbolic elements which accompany its functional spirit; decorations that give strength and magic to its users lives.

To make a ceramic dish memorial is a symbolic action. A dish in which we will possibly eat our future. Jodorowsky and especially Stephan Hausner, tell us about the contract couples make when they meet. They explain that most of our parents complex clauses are paid by children who try to compensate and solve situations, paying with their own healthy or living with no success.

These kind of educational artistic proposals bring back past stories in our pupils and also teachers families. There become some situations in school that allow us the biographic reconciliation and the creation of our links story which help us to give meaning and strength to live in the present; as Carles Parellada entrusts us from Systemic Pedagogy.

This activity was made by the Systemic Pedagogy master's degree pupils in Institut Gestalt and Fundació URV. We discovered the importance of our parents as a couple first meeting story in our own skin. Whatever happened between our parents, as it is our origin, it is important enough to know this story so we can create our own present life story. We incorporated systemic movements and we made exciting discoveries.

Keywords: Systemic Pedagogy; life stories; ceramics; family reconciliation; resilience; children art workshops. 
Larrencada: fer un plat i el conte del salze blau

Els cursos extraescolars dels tallers infantils d'art de l'escola Illa de Sabadell acullen infants i joves dels 6 als 15 anys.

A l'escola, a tots ens agrada molt fer ceràmica, i quan en fem, potser per la gran implicació corporal que comporta, sempre està molt vinculada a nosaltres: veiem la potència simbòlica del buit que generem en fer un pot i les coses que hi pintem sempre acaben parlant de nosaltres. En aquest cas, fer un plat de ceràmica és crear un recipient del qual menjarem i que tindrà una imatge pintada que serà un relat nostre i que ens acompanyarà en els àpats familiars.

Quan comencem un projecte sempre partim d'una recerca documental inicial d'imatges que fem amb els alumnes. Aquest cop, vam presentar una col-lecció d'imatges de plats ceràmica de totes les èpoques i cultures que expliquen relats i històries de vida. Hem aprofitat l'arxiu de plats que té el ceramista sabadellenc Benet Ferrer a Facebook (Ferrer, 2015). També ens van cridar l'atenció els relats de vida del ceramista britànic contemporani Grayson Perry i el treball de la pintora Fée Halsted a l'Ardmore Ceramic Art (2008) de Sud-àfrica, que expliquen els processos de vida d'adolescents malalts de sida.
En aquest cas, el disparador va ser la proposta del llibre Històries, de P. King i C. Roundhill (1998), que ens mostra el relat d'amor que hi ha amagat en els plats anglesos de porcellana d'imitació xinesa Spode del segle XIX, anomenats willow pattern.

En una il.lustració d'un paisatge fet amb blaus, hi ha el relat de la trista història d'amor de la rica Koong-se i Chang, el seu jardiner o comptable, la parella que fuig del pare, que soposa a la relació. Aquest els persegueix i finalment els mata. Després, els Déus, commoguts, els transformen en dos coloms. Aquest relat, conegut com The Story of the Willow Pattern, té fins i tot una novel-la policíaca, una obra de teatre i curts d'animació (Purves, 1992).

Cal dir que aquest treball va ser la continuació i la concatenació de diversos treballs anteriors fets per altres companyes, com l'Alèxia Garriga, que ho va provar en uns tallers d'extraescolars del col-legi Miquel Martí i Pol de Sabadell amb alumnes del cicle superior d'educació primària. O la Diana Font Puga, que ho va fer en la seva classe de P3 a l'escola Enric Casassas de Sabadell.

\section{Com es van conèixer els pares?}

Seguint les nostres intencions sistèmiques i amb voluntat de fer de l'aula un espai de reconciliació

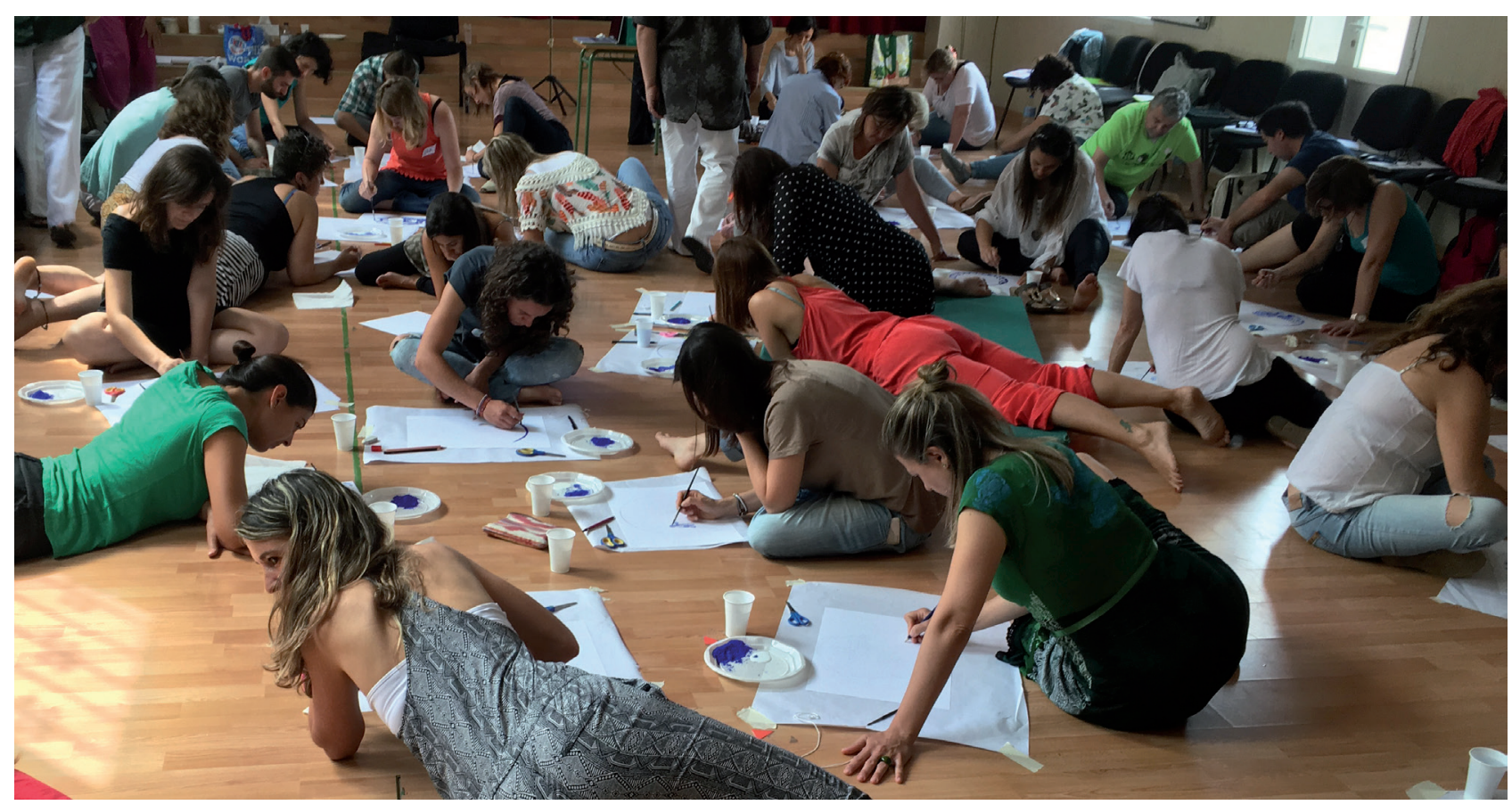

El silenci que es genera a l'aula quan fem una cosa que té a veure amb nosaltres 
biogràfica del nostre alumnat i les seves famílies, com bé diu Carles Parellada en les formacions que imparteix, ens vam fer una pregunta sobre la història d'amor més propera a nosaltres i que potser podem conèixer: com es van conèixer els nostres pares? En quin lloc es van veure per primer cop? Els vam proposar dibuixar sobre tot el moment i el lloc on els pares es van conèixer.

Sabíem que aquest tema tan misteriós seria un bon disparador intern de cada nen i nena, com ho ha sigut també per a nosaltres. El que realment va passar és que molts desconeixíem aquesta història. En una primera sessió de plantejament vam fer uns dibuixos en un paper rodó, $\mathrm{amb}$ forma de plat. Allà van aparèixer diverses idees, dubtes i també una gran particularitat de relats de vida: nens i nenes amb els pares separats o que no tenien pare o mare perquè eren morts, infants adoptats o fruit de tractaments de fecundació in vitro en famílies monoparentals. També vam informar les famílies que els nens anirien a casa amb aquesta pregunta, i alguns van tornar-ne amb relats complexos, diferents dels que havien dibuixat en un principi.

La manera com els nens entomen el projecte és sempre un misteri. Molts cops, veient com va l'aula, tenim l'equívoc de pensar que no s'interessen pel treball i que tot plegat és una catàstrofe. Són tan inesperades les capacitats expressives i la sensibilitat de cada un, que costa molt veure el que realment sí que està passant a l'aula.

És sorprenent com totes les històries, per variades que fossin, van tenir cabuda a l'aula. Moltes de les que van aflorar van ser formidables, es tractava de reconnectar amb aquell moment gràcies al qual avui som aquí. Aquest fet va desencadenar més relats dels professors i de diferents persones que pertanyen al centre: molts no sabíem la història i gràcies al projecte hem investigat i avui tenim la imatge del dia de la trobada dels nostres pares dins nostre, malgrat el que hagi passat posteriorment.

Jodorowsky i Costa (2011), en el seu llibre $\mathrm{Me}$ tagenealogía, diuen que quasi sempre els homes $i$ les dones es troben en un moment que podem anomenar inesperat i màgic. Les circumstàncies són tan increibles, i molts cops fora de control, que sembla que per escollir parella molts ens hà- gim begut l'enteniment. També remarquen que en les trobades de les futures parelles l'incident més insignificant i sense causes aparents té unes raons antigues que estan sotmeses a arrels que travessen diverses generacions; així, els noms s'atreuen curiosament i detalls aparentment menuts i anecdòtics són la causa que es produeixi la trobada de la nova parella.

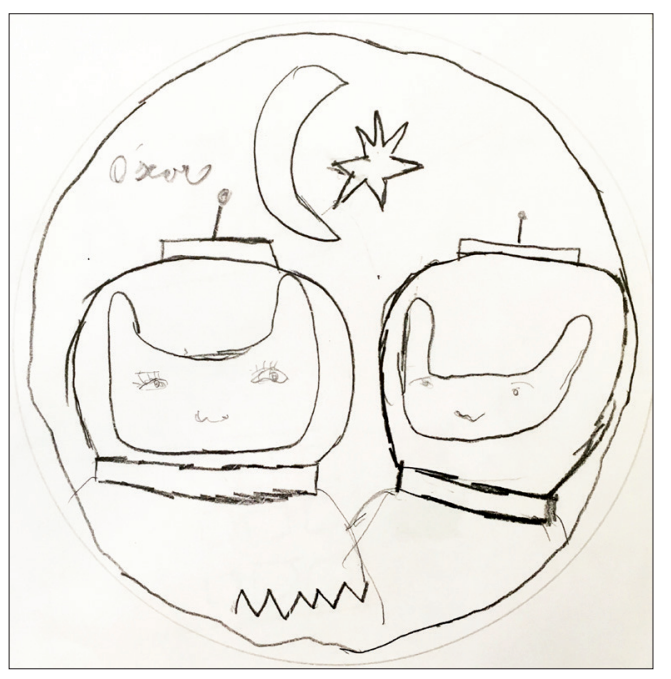

Els pares, dos astronautes en un món sense oxigen

Molts terapeutes, com Joan Garriga (2013) i, especialment, el constel-lador de la salut Stephan Hausner (2013; Franke, 2006), parlen d'aquest contracte inicial que hi ha des del primer moment a la parella. Ambdós ens conviden a mirar el que va passar des d'aquest primer moment perquè els fills paguem, compensant amb esforç i amb la fidelitat de voler pertànyer, i molts cops amb la salut, les misterioses clàusules d'aquest contracte inicial de la parella.

\section{Com es fa un plat?}

En el nostre taller, la tècnica és un recurs que cerquem a partir de les necessitats dels nostres projectes. En aquest cas ens hem plantejat fer un plat de ceràmica del qual podem menjar. Amb el suport de la ceramista del taller i de l'escola Illa, Maria Bosch, vam plantejar des del principi tot el procés artesanal com va ser. Vam fer servir un fang blanc de baixa temperatura al qual vam donar forma amb la tècnica de la premuda, treballant amb planxes aixafades amb un rodet i fent servir de motlle femella plats ja cuits que teníem per casa. 
També els vam voler pintar amb pigment blau d'engalba fent servir l'aiguada monocromàtica i l'esgrafiat com a recurs per crear els tons i línies que requeria cada disseny. Un cop sec, vam envernissar i coure el fang amb una sola enfornada a 800 graus, i amb aquesta màgia de la temperatura va passar a ser un plat de ceràmica. Heu de pensar que tot el procés és també un exercici amb la fragilitat: el plat de fang no cuit és molt delicat i la més mínima pressió el partirà per sempre. Quan surt del forn cuit i vitrificat és un èxit emocionant.

\section{Vídeo dels relats dels plats ja fets}

A la nostra escola procurem documentar tot el procés que es genera fotografiant els diferents moments del que va passant a l'aula, com una manera d'acostar-nos al que va passant i intentar surfejar la incertesa de les derives dels que formem part de l'aula.

Un cop cuits, emboliquem els plats a l'aula, però abans demanem als nens i nenes que ens expliquin en un petit vídeo aclaridor què està passant. Després de tot el procés i la seva documentació, provocar aquest relat oral del treball fet genera un tancament estètic que dóna sentit a tot el camí que l'alumne ha fet i ofereix comprensions internes i descobriments preciosos d'una petita part del que ha passat.

En mirar què havia passat vam veure que els alumnes que en un principi no van voler entrar en el tema, sobretot els adolescents, havien fet uns treballs amb més potència inconscient, potser més connectats amb la proposta.

Un noi rus adoptat, d'uns 14 anys, rigorosament tímid, va dibuixar el relat de tres nois que van anar a la muntanya i a qui els llops van matar. No em va saber respondre per què ho havia fet.

Destaco tres exemples de les moltes coses que van succeir:

Un nen molt guerrer va posar en el plat Darth Vader (el pare dolent de La guerra de les galàxies) sota la parella dels pares i em va explicar que Darth Vader és el pare que s'ha tret el casc de dolent per acostar-se a la mare...

El dibuix d'un drac envoltant un ou va ser la representació d'un nen fruit d'una fecundació in vitro en una família monoparental: el drac protegeix l'essència que el pare absent va aportar perquè ell fos aquí.
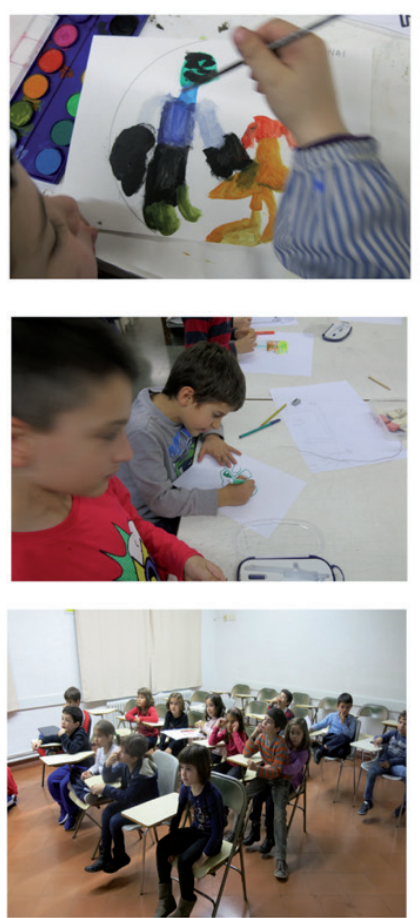
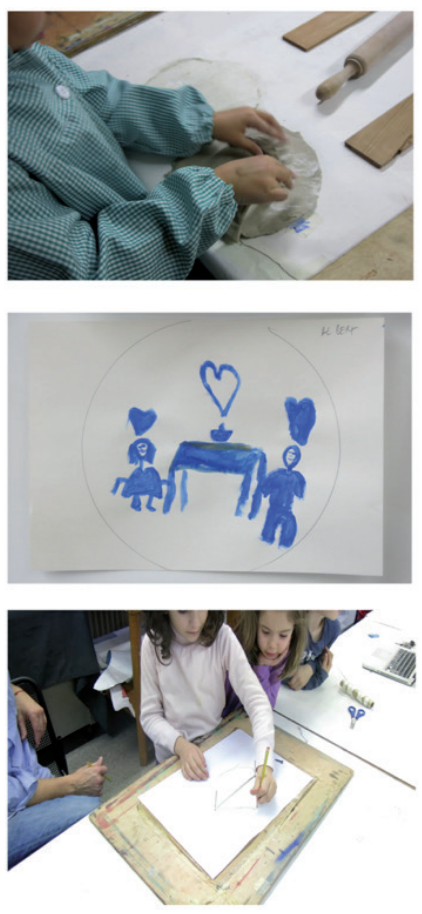
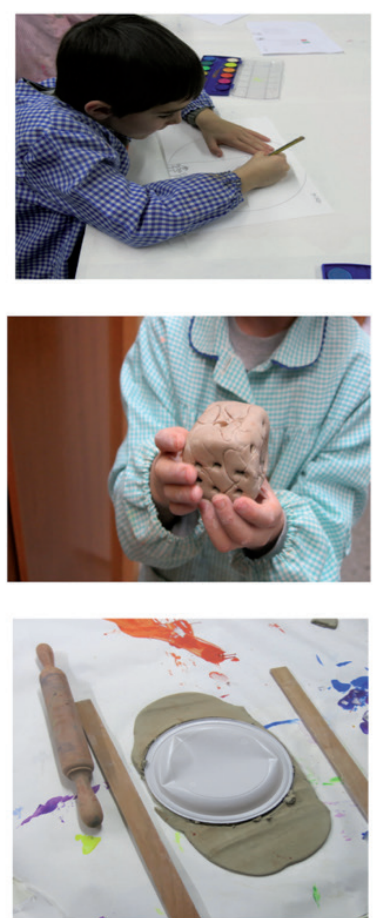

Plantejament i treball amb ceràmica 
Un nen a qui el pare se li va morir de molt petit va dibuixar el seu pare amb el braç cremat. Es va posar molt nerviós, ens va dir que sabia poques coses del seu pare i que el poc que en sabia era aquest accident. La mare ens va explicar posteriorment que li havien explicat tot, la història del coneixement del seu pare biològic i sobretot del pare l'actual. En tot cas, després d'això, vist l'embolic, el nen no va voler saber res més d'aquest projecte.

Aquests reculls del nostre alumnat ens recorden el que deien Viktor Frankl (1946) i posteriorment Boris Cyrulnik (2009): que les claus de la resiliència són dos fets, el vincle i els relats que ens fem.

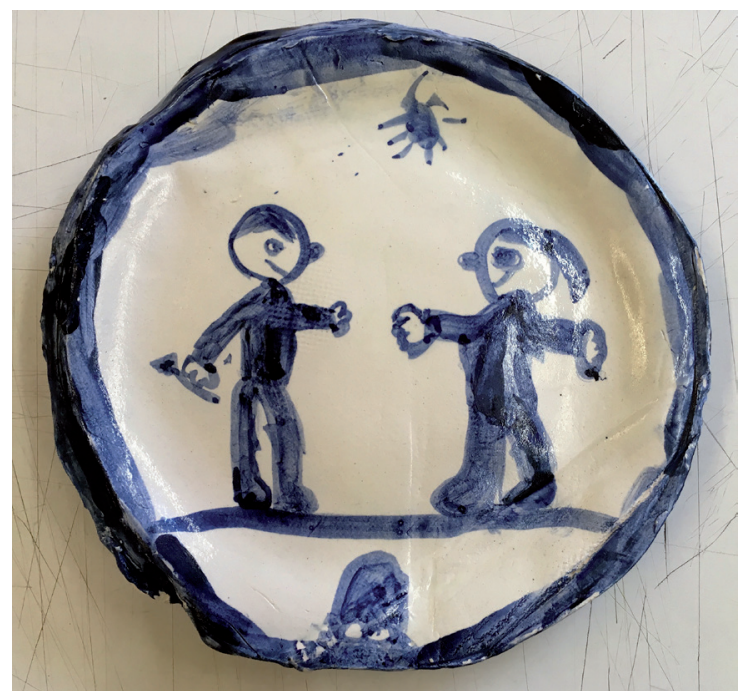

El pare deixa de ser Darth Vader per acostar-se a la mare

\section{I per què no ho fem els mestres?}

Seguidament, en un curs de formació de mestres sobre art i emocions que vaig fer a la primavera en una escola de Sabadell, vaig plantejar l'exercici, un cop més sense avisar.

En aquest cas vam fer el projecte dibuixant el plat en un paper de pintura rodó, que vam pintar a l'aiguada amb pigment blauet amb aigua i cola blanca. Tot i ser adults, el factor sorpresa ajuda a treure una informació complicada, i potser en alguns casos no ha sigut fàcil. A poc a poc es van desvetllant els relats i comencen a crear una imatge del que creuen que va passar.

En els dibuixos descobrim les peculiaritats de les trobades amb els detalls rellevants: si la mi- rada va ser important; qui va dir la primera paraula ("li va demanar l'hora"); si es van conèixer ballant o través d'un amic o amiga, d'una juguesca d'enfrontament, d'un germà o dels pares; si es van trobar sols o enmig de la família; si deixaven una altra parella...

També va fer el seu efecte albirar la màgia $\mathrm{i}$ la valentia de la trobada que ens va portar a la vida: el risc dels que creen la parella malgrat les dificultats dels sistemes familiars, que la relació no va ser fàcil i ja va començar amb dubtes i amb tensions a les dues famílies i que potser va acabar malament.

Va ser molt interessant sentir com una mestra va fer aparèixer la reflexió: "Si per mi com a filla és tan important saber el relat de fundació de la parella que són els pares, ara entenc la insistència dels meus fills per saber".

Les mestres de més edat es van emocionar dibuixant i explicant relats de boniques històries, moltes d'un món rural avui desaparegut.

\section{Plats dels pares, mestres i moviments sistèmics}

Fent un pas més, a Mallorca, amb l'alumnat del primer curs de formació en pedagogia sistèmica de l'Institut Gestalt, vaig plantejar l'exercici del dia de la trobada dels pares en un grup d'unes 45 persones compost per mestres, educadors i terapeutes. En aquest cas, també fem el disseny amb pigment blauet i cola, retallem el plat i ens quedem una estona amb el plat a les mans.

Després els vaig proposar de fer un treball d'investigació en grups de tres persones en el qual les companyes que no coneixien res de la vida de la persona que representaven feien de pare o de mare el dia que es van veure per primer cop. Seguint la tècnica dels moviments sistèmics, el representat col-locava en una posició les persones que representaven els seus pares, després es deixaven sentir i feien el que sentien corporalment.

Un cop més, va ser impressionant, es va moure molta informació, coses sabudes es van confirmar i també va aparèixer nova informació que semblava que ja no estava disponible.

Hi va haver una mestra que va veure emocionada uns pares avui desapareguts molt enamorats, quan sempre li havien dit que no es porta- 
ven gens bé. Pares que es van conèixer caminant i que es van posar a caminar només començar el treball, pares balladors que no podien estar-se quiets...

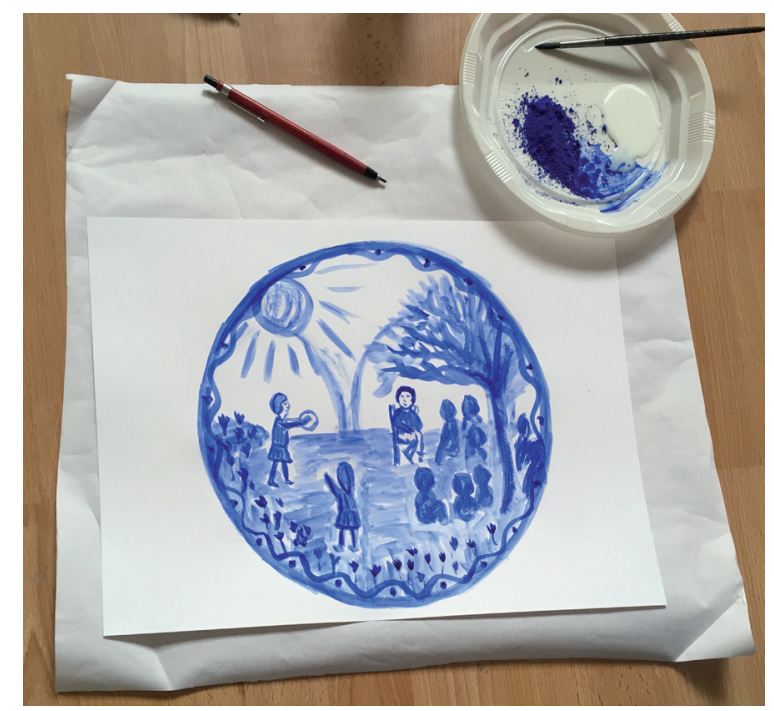

Plat amb pigment blauet $i$ cola blanca

Una mestra va descobrir amb tristor uns pares molt poc romàntics, més aviat materialistes. La mare deia: "Es veu un bon noi i amb recursos"; i el pare deia: "Es veu una bona noia, forta i treballadora".

Aquesta tristor es va veure també en altres històries, potser perquè veien que hi havia una repetició de patrons d'estil de parella en les pròpies històries que estaven vivint en la seva vida actual.

Aquesta proposta també la van portar a terme a Reus amb l'alumnat del màster en Educació Sistèmica Multidimensional de la Fundació URV.

\section{Conclusions}

Per fer aquest treball d'experiència genealògica hem utilitzat el món de l'art, amb el dibuix i el fang, un recurs que neguiteja molts mestres perquè se senten poc formats. Al principi hi ha una gran reticència a causa de males experiències anteriors, de quan eren escolars; després, quan mirem el que hem fet, es queden sorpresos de les capacitats expressives de les produccions dels companys, i els companys de les seves. Com puntualitza Alfredo Hoyuelos (2015) en parlar de Loris Malaguzzi, quan utilitzem l'art emergeixen els cent llenguatges dels nens, i jo hi afegiria: i de les persones adultes. Fa goig veure tota la producció de la classe junta, un conjunt potent amb una varietat i riquesa que es complementen, en el qual tothom aporta i té el seu lloc amb la seva especial complexitat familiar.

Com distingeix Malaguzzi, podem gaudir de les moltes competències de l'art: la improvisació i la flexibilitat en la creació, la connexió entre les parts, el fet que no hi hagi una pregunta per a una sola resposta, la interpretació mútua de forma i contingut, i, sobretot, l'oportunitat de donar temps a cada persona per descobrir allò que internament busca.

Com que som animals simbòlics, en aquest treball quedem sorpresos de les nostres capacitats de llegir els treballs dels companys. Si facilitem una conversa al voltant d'un dibuix, podem veure emergir molta informació de l'inconscient de qui l'ha fet. Aquesta conversa permet comprendre, de manera que el dibuix es converteix en una experiència estètica que genera i ens desperta un coneixement sobre la realitat.

En tot cas, majoritàriament, va ser un treball donador d'energia interna: va permetre descobrir que venim de la misteriosa energia jove dels nostres pare i mare, una energia portadora d'una gran curiositat i força cap a la vida. Podríem dir que som fruit de quasi herois, que van superar valentament, en molts casos i per un moment, les energies i tensions dels dos arbres genealògics que ens han creat. Un cop més, l'expressió serveix per fer emergir una emoció interna que molts relats familiars ens han negat, per descobrir que som fruit d'una misteriosa trobada que va portar el nostre infant lluminós a la vida.

John Dewey $(1985,2008)$ i posteriorment Humberto Maturana (2008) ja somiaven que si som capaços d’organitzar l'aula en un espai democràtic de conversa on tothom és reconegut per allò que porta del seu sistema familiar, i hi té un lloc per ser i per crear, no caldrà fer res per canviar el món, ells mateixos seran portadors del canvi. 


\section{Referències bibliogràfiques}

Ardmore Ceramic Art (2008). Pàgina web [En línia]. [Data de consulta: 12-01-2015]. $<$ http://www.ardmoreceramics.co.za/worldof-ardmore/community-support>

Cyrulnik, B. (2009). El encantamiento del mundo. Barcelona: Gedisa.

Dewey, J. (1985). Democràcia i escola. Vic: Eumo.

Dewey, J. (2008). El arte como experiencia. Barcelona: Paidós.

Ferrer, B. (2015). Pàgina a Facebook [En línia]. [Data de consulta: 19-02-2015]. <https://www. facebook.com/benet.ferrerboluna?fref $=\mathrm{ts}>$

FrankL, V. (1946). El hombre en busca de sentido. Barcelona: Herder.

Franke, M. (2006). Entrevista a Stephan Hausner: Curación en sintonia [En línia]. [Data de consulta: 08-03-2014]. <http://docplayer. es/14130092-Entrevista-a-stephan-hausner. html>

Garriga, J. (2013). El buen amor en la pareja. Barcelona: Destino.

Hausner, S. (2013). Aunque me cueste la vida. Buenos Aires: Alma Lepick.
Hoyuelos, A. (2015). El taller de expresión y Loris Malaguzzi. Reflexiones sobre la relación entre niños, arte y artistes [En línia]. [Data de consulta: 28-02-2015]. <http://docplayer. es/8256162-El-taller-de-expresion-y-lorismalaguzzi-reflexiones-sobre-la-relacionentre-ninos-arte-y-artistas-1-alfredo-hoyuelos-2.html>

Jodorowsky, A. i Costa, M. (2011). Metagenealogía. Madrid: Siruela.

King, P. i Roundhill, C. (1998). Històries. Barcelona: Parramón. (Taller d’art)

Maturana, H. (1998). Emociones y lenguaje en educación y política [En línia]. [Data de consulta: 19-01-2015]. <http://turismotactico. org/proyecto_pologaraia/wp-content/uploads/2008/01/emociones.pdf>

Purves, B. [dir.] (1992). Screen Play [En línia]. [Data de consulta: 20-10-2014]. <https:// www.youtube.com/watch? $=\mathrm{t} 0 \mathrm{~d} 1 \mathrm{EsHJH9Q>}$

The Willow Pattern Story [En línia]. [Data de consulta: 30-11-2014]. <http://www.thepotteries.org/patterns/willow.html>
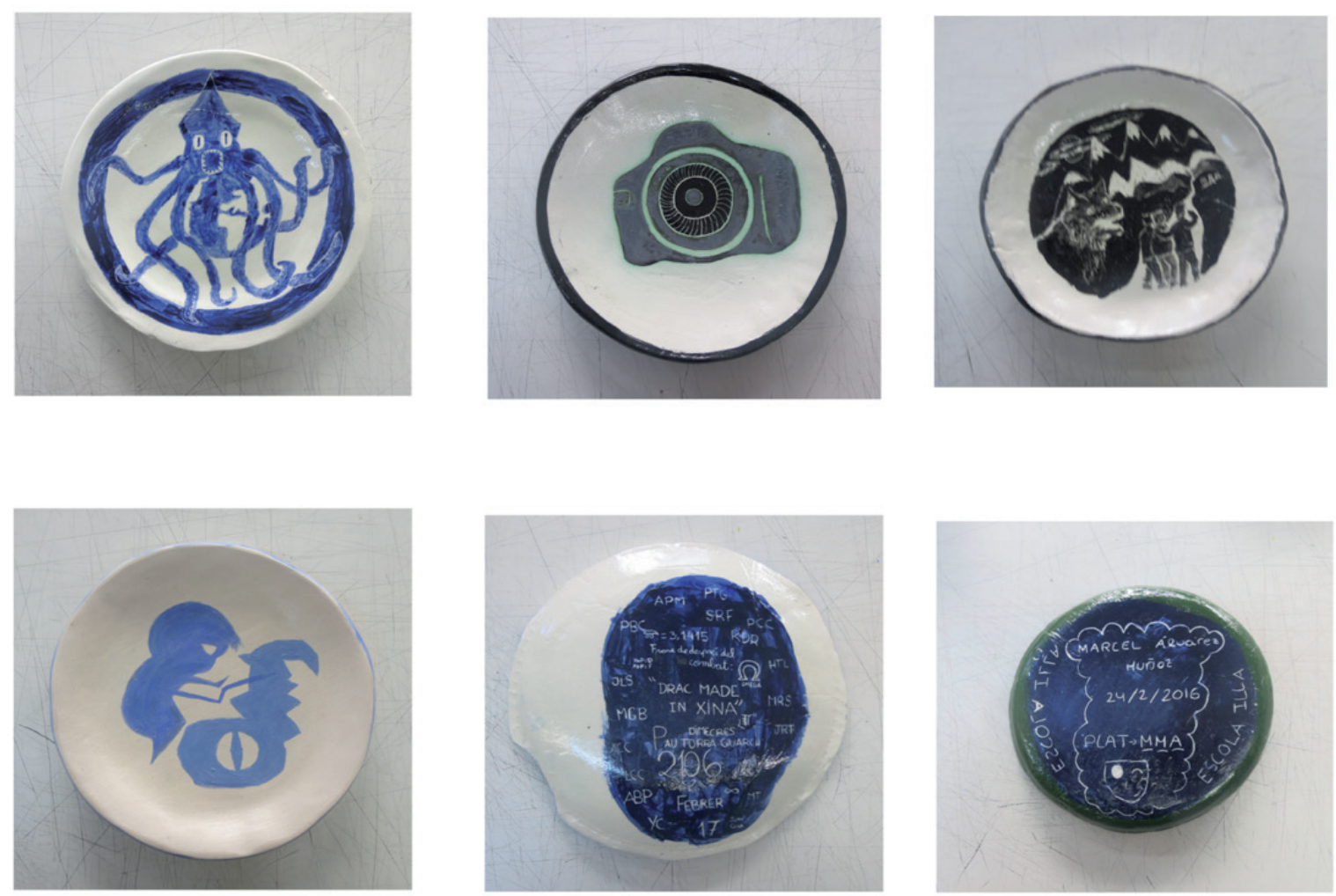

Plats dels adolescents dels pares 